\title{
PREVENTION OF FERTILIZATION IN VITRO BY AN ACROSIN INHIBITOR FROM RETE TESTIS FLUID OF THE RAM
}

\author{
J. SUOMINEN,* M. H. KAUFMAN† AND B. P. SETCHELL \\ Department of Biochemistry, A.R.C. Institute of Animal Physiology, \\ Babraham, Cambridge, and $\dagger$ Physiological Laboratory, Cambridge
}

(Received 21st March 1973)

One of the enzymes probably involved in sperm penetration through the outer layers of the ovum is a trypsin-like enzyme, called acrosin because of its location in the acrosome. This enzyme is inhibited by substances found in semen and in the secretion of seminal vesicles of several mammalian species (see Werle \& Zickgraf-Rüdel, 1972). It is generally thought that the spermatozoa mix with these inhibitors during ejaculation, and a complex between the inhibitors and the acrosin is formed at that time (Zaneveld, Polakoski, Robertson \& Williams, 1971; Werle \& Zickgraf-Rüdel, 1972). Removal of these inhibitors from the acrosome is supposed to be an essential part of the process of capacitation and the acrosome reaction (see Bedford, 1970). Several attempts have been made to prevent fertilization with synthetic or natural trypsin inhibitors, and most of these experiments have been successful (Stambaugh, Brackett \& Mastroianni, 1969; Zaneveld, Polakoski, Robertson \& Williams, 1971; Zaneveld, Robertson, Kessler \& Williams, 1971).

We have found a high concentration of trypsin inhibitor in the fluid collected from the rete testis of rams and boars (Suominen \& Setchell, 1972), and it would appear therefore that the spermatozoa are exposed to trypsin inhibitors from the moment they leave the testis. This inhibitor from the rete testis fluid (RTF) of the ram has been purified and characterized; it can be separated into three fractions (I, II and III) by CM-cellulose chromatography, but all three inhibitor fractions have similar characteristics. They do not inhibit any other common proteolytic enzyme apart from trypsin (i.e. chymotrypsin, plasmin, kallikrein, thrombin or urokinase), their molecular weight is about 6500 , they are very stable and they are probably polypeptides (Suominen \& Setchell, in preparation).

The present experiments were carried out to see whether these inhibitors were able to prevent fertilization in vitro. The inhibitors were purified from the RTF of the ram as described by Suominen \& Setchell (in preparation). The effect of the RTF inhibitors on fertilization was tested in vitro using mouse ova and epididymal spermatozoa (Kaufman, 1973) incubated in a defined medium (Whittingham, 1971). To this culture medium, different amounts of RTF inhibitor II were added; this inhibitor fraction was chosen for experiment because it contained the highest inhibitor activity $(88.7 \mathrm{inh} . \mathrm{mU} / \mathrm{ml} ; 1$ inhibitor

* Present address: Department of Anatomy, University of Turku, Turku, Finland. 


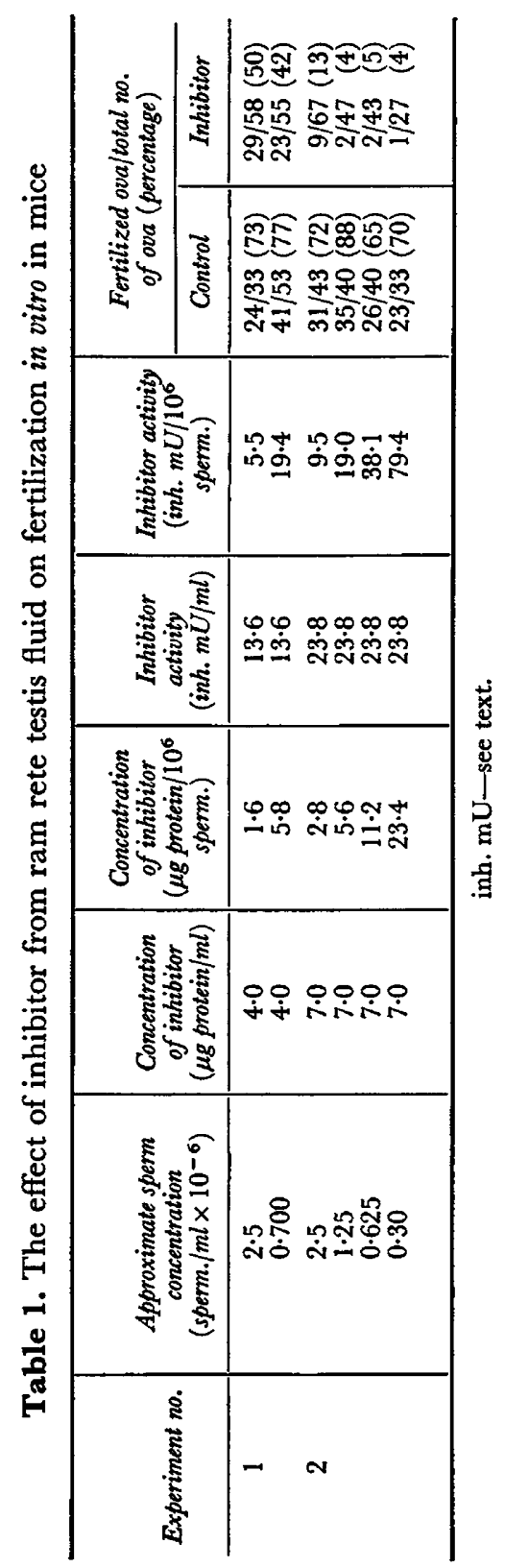


milliunit is the amount of inhibitor which reduces the hydrolysis of $\mathcal{N}$-benzoylDL-arginine-p-nitroanilide (BAPA) by trypsin by $1 \mathrm{nmol} / \mathrm{min}$ at $+37^{\circ} \mathrm{C}$ ). Its protein concentration was $26 \mu \mathrm{g} / \mathrm{ml}$. The controls contained an equivalent volume of $0.9 \% \mathrm{NaCl}$; in other experiments, other non-inhibitory fractions from the GM-cellulose chromatography were shown to have no effect on fertilization.

When the concentration of the inhibitor was similar $(23.8 \mathrm{inh} . \mathrm{mU} / \mathrm{ml})$ to that in RTF (24.1 to 27.2 inh. $\mathrm{mU} / \mathrm{ml}$ ), fertilization was effectively blocked (Table 1). The results also suggest that fertilization was inhibited more effectively when the number of spermatozoa used was smaller and the inhibitor concentration was kept at the same level, i.e. when the amount of the inhibitor per spermatozoon was higher. At lower inhibitor concentration (one sixth of that occurring in the RTF), a slight but distinct reduction in fertilization rate was also noted.

Our results confirm the earlier findings of Stambaugh et al. (1969) on the effect of trypsin inhibitors on fertilization in vitro. These authors, however, used trypsin inhibitors derived from soybean and ovomucoid, and a high concentration $(0.5$ to $1.0 \mathrm{mg} / \mathrm{ml})$ of these inhibitors was needed before fertilization was prevented. Zaneveld, Polakoski, Robertson \& Williams (1971) and Zaneveld, Robertson, Kessler \& Williams (1971), using an in-vivo technique, found that fertilization was effectively reduced by inhibitors purified from rabbit seminal plasma or from seminal vesicles at low concentrations, about the same as those used by us, 1.0 to $2.5 \mu \mathrm{g} / 10^{3}$ spermatozoa. Schumacher, Swartwout \& Zuspan (1971) failed to block fertilization with polyvalent trypsin-kallikrein inhibitor (Trasylol ${ }^{\infty}$ ) or with soybean trypsin inhibitor when incubated with ejaculated spermatozoa or given systemically into rabbits. Their negative result could be partly explained by our finding that inhibitors purified from the RTF are more effective against acrosin than is trypsin-kallikrein inhibitor (Trasylol ${ }^{\star}$ ). This may be true also in the case of inhibitors occurring in semen or in the secretion of the seminal vesicles.

It is clear, therefore, that the inhibitor in the RTF is effective in blocking fertilization, and the testis may be the source of the decapacitation factor in epididymal seminal plasma. It is now necessary to determine why these testicular inhibitors are less tightly bound to the spermatozoa than the inhibitors in ejaculated seminal plasma.

We are grateful to the Underwood Fund for a grant to enable J.S. to come to England to do this work.

\section{REFERENCES}

Bedford, J. M. (1970) Sperm capacitation and fertilization in mammals. Biol. Reprod. Suppl. 2, 128. Katrman, M. H. (1973) Timing of the first cleavage division of the mouse and the duration of its component stages: A study of living and fixed eggs. Fnl Cell Sci. 12, 799.

Schumacher, G. F. B., Swartwout, J. R. \& Zuspan, F. P. (1971) Fertility experiments with the trypsinkallikrein inhibitor from bovine lung. In: Proc. int. Res. Conf. on Proteinase Inhibitors, Munich, 1970, p. 247. Eds. H. Fritz and H. Tschesche. W. de Gruyter \& Co., Berlin and New York.

Stambaugh, R., Bracketr, B. G. \& Mastroianni, L. (1969) Inhibition of in vivo fertilization of rabbit ova by trypsin inhibitors. Biol. Reprod. 1, 223. 
Suominen, J. \& Setchell, B. P. (1972) Enzymes and trypsin inhibitor in the rete testis fluid of rams and boars. F. Reprod. Fert. 30, 235.

WERLE, E. \& ZICKGRAF-RüDEL, G. (1972) Natural proteinase inhibitors. Distribution, specificity, mode of action and physiological significance. Z. klin. Chem. E klin. Biochem. 10, 139.

Whittingham, D. G. (1971) Gulture of mouse ova. F. Reprod. Fert. Suppl. 14, 7.

Zaneveld, L. J. D., Polakoski, K. L., Robertson, R. T. \& Williams, W. L. (1971) Trypsin inhibitors and fertilization. Proc. int. Res. Conf. on Proteinase Inhibitors, Munich, 1970, p. 236. Eds. H. Fritz and H. Tschesche. W. de Gruyter \& Co., Berlin and New York.

Zaneveld, L. J. D., Robertson, R. T., Kessler, M. \& Williams, W. L. (1971) Inhibition of fertilization in vivo by pancreatic and seminal plasma trypsin inhibitors. F. Reprod. Fert. 25, 387. 